\title{
Avaliação dos stakeholders em relação às mudanças na legislação ambiental e reforma do Código Florestal Brasileiro
}

\section{Evaluation of Stakeholders in Relation to \\ Changes in Environmental Legislation and the Reform of Brazil's Forest Code}

\author{
Oriana Trindade de ALMEIDA* \\ Thiago Bandeira CASTELO** \\ Sérgio Luiz de Medeiros RIVERO***
}

\begin{abstract}
RESUMO
O setor florestal tem sofrido grande impacto com mudanças nas leis que regem as atividades florestais nacionais e estaduais, a exemplo da Lei $\mathrm{n}^{\circ} 11.284 / 2006$, de gestão de florestas públicas, e a atual discussão sobre a mudança no principal instrumento da legislação florestal (o Código Florestal). A reforma do Código Florestal ( $\mathrm{PL} \mathrm{n}^{\mathrm{o}}$ 1.876/99) gerou grandes polêmicas entre aqueles que são a favor ou contra sua reforma nas diversas camadas da sociedade brasileira, com destaque para ambientalistas e agropecuaristas que defendem posicionamentos divergentes sobre os rumos da política florestal nacional. Para verificar esta hipótese, foram realizadas entrevistas abertas com técnicos e pesquisadores que trabalham direta ou indiretamente com ensino, pesquisa e gestão das áreas de florestais em nível estadual a fim de determinar quais os problemas da legislação ambiental, com destaque para a legislação florestal vigente, e propor melhorias para o setor florestal na região Amazônica. Os dados obtidos mostraram que não há consenso sobre as mudanças na legislação florestal. Os pesquisadores e técnicos acham inadequadas as propostas de reforma do Código Florestal e o processo de descentralização da gestão florestal para o Estado do Pará precisa de adequações, como desburocratização das ações administrativas e aplicabilidade das leis pelos órgãos competentes.
\end{abstract}

Palavras-chave: legislação ambiental; floresta; Código Florestal; políticas.

\footnotetext{
" Doutora em Ciências Socioambientais (UL, Inglaterra). Professora do Núcleo de Altos Estudos Amazônicos (NAEA) da Universidade Federal do Pará (UFPA). E-mail: oriana@ufpa.br

** Graduando em Ciências Econômicas (UFPA). Bolsista do Programa Institucional de Bolsas de Iniciação Científica - PIBIC/CNPq no Núcleo de Altos Estudos Amazônicos (NAEA) da Universidade Federal do Pará (UFPA). E-mail: thiagobcastelo@gmail.com

*** Doutor em Desenvolvimento Sustentável do Trópico Úmido (UFPA). Professor do Programa de Pós-Graduação em Economia da Universidade Federal do Pará (UFPA). E-mail: sergiolmrivero@gmail.com
} 


\begin{abstract}
The forestry sector has suffered big impact with changes in laws governing the national and state forest activities, such as the Law n. 11.284/2006 on management of public forests and the current discussion about changing the main tool of forest legislation (the Forest Code). The reform of the forestry code has generated great polemics between those for and against reform in its various strata of Brazilian society, especially environmentalists and ranchers who hold differing positions on the direction of national forest policy. To verify this hypothesis, we conducted interviews with researchers and technicians who work directly or indirectly with teaching, research and management of forest areas at the state level to determine which are the problems of environmental legislation, highlighting the current forest legislation, and propose improvements to the forest industry in the Amazon region. The data showed that there is no consensus on the changes in forest legislation. Researchers and technicians find inadequate the proposals for reform of the forestry code, and the process of decentralization of forest management for the State of Pará needs adjustments such as streamlining of administrative actions and applicability of laws by the relevant bodies.
\end{abstract}

Keywords: environmental law; forest; Forest Code; policies.

\section{Introdução}

A legislação florestal vem passando por constantes mudanças ao longo das décadas. Essas mudanças afetam diretamente os atores ligados à gestão de manejo, como os técnicos das instituições que monitoram e controlam a exploração das áreas ambientais, assim como pesquisadores que atuam na área. Neste cenário, o papel do governo brasileiro diante do avanço desordenado do desmatamento na região amazônica é fundamental. Em nível federal, o Instituto Brasileiro do Meio Ambiente e dos Recursos Naturais Renováveis - IBAMA (Lei ${ }^{\circ}$ 7.735/1989) tem atuado na proteção do meio ambiente, assegurando a sustentabilidade no uso dos recursos naturais e promovendo qualidade ambiental em todo território nacional. Porém, a necessidade de descentralização das ações administrativas em função da grande extensão do território brasileiro, que sobrecarregava as ações fiscalizadoras do IBAMA, levou à publicação da Lei $\mathrm{n}^{\circ} 11.284 / 2006$ de gestão de florestas públicas, que inovou através do processo de descentralização da gestão florestal da União para os Estados e municípios.

Posteriormente a isso, atores do meio rural, como fazendeiros e empresários, com apoio político de alas do governo, abriram as discussões sobre a renovação no Código Florestal de 1965. Novas formas que visam suprir a necessidade de crescimento do país em paralelo com a proteção do meio ambiente têm sido colocadas em discussão. Porém, os interesses existentes dos vários grupos sociais geraram um debate controverso sobre o tema, opondo principalmente o interesse dos produtores rurais e os interesses dos grupos conservacionistas. Em 2011, o Congresso Nacional discutiu a modificação do Código Florestal Brasileiro. O Projeto de Lei n ${ }^{\circ} 1.876 / 1999$, de relatoria do deputado federal Aldo Rebelo (PCdoB-SP), propôs grandes mudanças no cenário agroflorestal brasileiro. No debate político, duas posições políticas em relação à nova proposta surgiram e se definiram como a bancada ruralista e, diametralmente oposta, a bancada

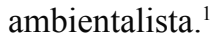

As propostas de mudanças do Código Florestal causaram grandes debates e questionamentos por parte dos ambientalistas. As cinco principais mudanças propostas eram relacionadas à: a) diminuição das Áreas de Proteção Permanente - APPs, b) anistia aos crimes ambientais, c) isenção de reserva legal para imóveis com até quatro módulos fiscais em todo o país, d) redução da reserva legal na Amazônia em áreas com vegetação; e e) compensação de áreas desmatadas de passivos florestais em um Estado por áreas de floresta em outros Estados ou bacias hidrográficas (SOS FLORESTAS, 2011).

${ }^{1}$ Projeto de Lei 1.876/1999. Disponível em: <http://www.camara.gov.br/proposicoesWeb/fichadetramitacao?idProposicao =17338>. Acesso em: 03/06/2012. 
Depois de inúmeros embates políticos que avaliaram as propostas de mudança do Código Florestal, o novo texto do código foi aprovado em maio de 2012 (Lei Federal $\left.n^{\circ} 12.651 / 2012\right)$. Esse texto trouxe algumas modificações importantes relacionadas à anistia aos desmatadores e à flexibilização no uso das APPs. Com a finalidade de apresentar a evolução das leis ambientais e o cenário recente do Código Florestal, este trabalho fez uma análise da percepção dos stakeholders (grupos de interesse) sobre as mudanças sofridas pela legislação ambiental e o impacto de tais mudanças sobre as instituições e órgãos de gestão ambiental, com destaque para a legislação florestal e as propostas inicialmente discutidas sobre a reforma do Código Florestal.

\section{Metodologia}

Para esse trabalho, foram realizadas entrevistas semiestruturadas e detalhadas com técnicos e pesquisadores que trabalham direta ou indiretamente com pesquisa, ensino e gestão das áreas florestais no nível estadual na cidade de Belém, Estado do Pará. Essas entrevistas foram estruturadas após análise documental (legislação ambiental como um todo, Código Florestal e sua atual reforma) e revisão da literatura sobre a temática. Ocorreram em três órgãos de gestão ambiental e quatro instituições de ensino e pesquisa estadual, respectivamente: Instituto de Desenvolvimento Florestal do Estado do Pará (IDEFLOR), Secretaria de Estado de Meio Ambiente (SEMA), Instituto Brasileiro do Meio Ambiente e dos Recursos Naturais Renováveis (IBAMA), Museu Paraense Emílio Goeldi (MPEG), Universidade do Estado do Pará (UEPA), Universidade Federal do Pará (UFPA) e Universidade Federal Rural da Amazônia (UFRA). O grupo de entrevistados foi composto por sete técnicos que ocupam cargos de gestão nos órgãos ambientais e dez pesquisadores de centros e universidades públicas do Estado do Pará, sendo chamados de stakeholders - grupos de interesse sobre os quais a pesquisa visou colher informações.

A escolha dos pesquisadores se deu através de sua formação acadêmica, conhecimento sobre o tema e linhas de atuação. Os pesquisadores avaliados possuíam vasto entendimento sobre o tema, sendo graduados obrigatoria- mente em Engenharia Agronômica, Engenharia Florestal ou Economia. Suas principais linhas de pesquisas eram: legislação ambiental, desenvolvimento agrícola, gestão de áreas protegidas, botânica aplicada, entre outras. Em relação aos técnicos, todos foram estrategicamente escolhidos. A escolha se baseou em tempo de serviço na função no órgão ambiental, atividades ligadas ao setor madeireiro e importância do cargo frente ao órgão ambiental (cargos de gestão). Foi realizado, com os técnicos, um número menor de entrevistas, porque a metodologia se constituiu de perguntas abertas para maior entendimento das análises pessoais sobre o código e suas mudanças. Um questionário semiestruturado também foi aplicado aos entrevistados, contendo perguntas relacionadas: i) à evolução da legislação ambiental; ii) às mudanças positivas e negativas atuais na legislação por meio do Código Florestal; iii) aos impactos no setor ou pesquisa dos grupos de interesse e descentralização da gestão de manejo florestal; iv) ao sistema de concessão florestal; e v) à autonomia estatal para legislar sobre as questões ambientais.

As questões objetivas foram tabuladas segundo frequência de respostas para todos os entrevistados. As respostas subjetivas foram agrupadas segundo similaridade e usadas para dar mais detalhes a cada pergunta objetiva. As entrevistas ocorreram em Belém, entre agosto de 2011 e maio de 2012.

\section{Evolução das leis ambientais brasileiras}

\subsection{Principais instrumentos legais de proteção ao meio ambiente}

Segundo Medeiros (2006), "os primeiros dispositivos voltados à proteção de áreas ou recursos em terras brasileiras têm seu registro ainda no período colonial". O principal objetivo era a garantia do controle sobre o manejo de determinados recursos, como a madeira ou a água, como era praticado em algumas partes da Europa (MEDEIROS, 2006).

Em meados da década de 1930 tornaram-se necessários dispositivos de controle e proteção para áreas ambientais. Com base no mesmo raciocínio, a busca por 
meios eficientes para a preservação ambiental levou em 1934 à aprovação do texto do Código Florestal brasileiro (Decreto $\mathrm{n}^{\circ}$ 23.793/34). Sobre isto, Medeiros (2006) mostra que as aspirações conservadoras ficaram registradas na segunda constituição republicana brasileira de 1934, onde, pela primeira vez, a proteção da natureza figurava como um princípio fundamental, tanto para a União como para os Estados. De responsabilidade da União e dos Estados ficaria a proteção das belezas naturais e monumentos de valor histórico e artístico. Isto estava tratado de maneira sucinta na Constituição de 1934, porém outorgava à natureza um novo valor, passando a ser considerada um patrimônio nacional. Neste contexto, os principais dispositivos legais criados na época para proteção da natureza foram: 1) Código Florestal (Decreto $\left.n^{\circ} 23.793 / 34\right)$; 2) Código das Águas (Decreto n $\left.{ }^{\circ} 24.643 / 34\right)$; 3 ) Código de Caça e Pesca (Decreto $\left.n^{\circ} 23.793 / 34\right)$ e o decreto de proteção aos Animais (MEDEIROS, 2006).

Em 1964, o novo Código Florestal foi revisto e aprovado (Lei ${ }^{\circ}$ 4.771/65), o que constitui uma grande mudança, pois são extintas as quatro tipologias de áreas protegidas antes previstas na versão de 1934, substituindo-as por quatro outras novas: Parque Nacional e Floresta Nacional (anteriormente categorias específicas), as Áreas de Preservação Permanente (APP) e a Reserva Legal (RL) (MEDEIROS, 2006). A segunda grande mudança se deu em 1981, quando foi estabelecida a Política Nacional do Meio Ambiente (Lei ${ }^{\circ}$ 6.938/81), que consolida e amplia as conquistas nas esferas estadual e federal. Para Monteiro, (2007), "a legislação ambiental brasileira divide-se em dois momentos bem distintos: antes e depois de 1981".

Antes mesmo da Política Nacional do Meio Ambiente em 1981, Medeiros (2006) fala que em 1973 foi criada a Secretaria Especial do Meio Ambiente (SEMA), vinculada ao Ministério do Interior, sob o impacto dos debates decorrentes da Conferência de Estocolmo. A criação da SEMA demonstra a preocupação do governo em debater políticas voltadas ao meio ambiente e aumento de instrumentos legais para proteção da natureza juntamente com órgãos gestores para monitorar a aplicação das leis. A princípio, era previsto à SEMA assumir a gestão de Unidades de Conservação e o IBDF assumiria a parte de fomento. Como a parte da gestão das unidades de conservação continuou com o Instituto Brasileiro de Desenvolvimento Florestal (IBDF), esse processo resultou na proposição inicial de quatro novas tipologias de áreas protegidas pela SEMA: as Estações Ecológicas (ESEC) e as Áreas de Proteção Ambiental (APA), em 1981, além das Reservas Ecológicas (RESEC) e das Áreas de Relevante Interesse Ecológico (ARIE), em 1984. Mais tarde, em 1996 e já com a SEMA alçada ao status de Ministério, foram criadas as Reservas Particulares do Patrimônio Natural (RPPNs), uma nova tipologia que permitia o reconhecimento de uma área protegida em domínio privado (Quadro 1).

\subsection{O Código Florestal brasileiro e a política nacional de meio ambiente}

O Código Florestal foi aprovado pela primeira vez em 1934 e partiu do pressuposto de que a conservação das florestas e dos outros ecossistemas naturais interessa a toda a sociedade (SOS FLORESTAS, 2011). Segundo Ahrens (2003), "o Código Florestal de 1934 (Decreto $\mathrm{n}^{\circ}$ 23.793, de 23-01-1934)2 resultou de um anteprojeto elaborado por uma Comissão cujo relator foi Luciano Pereira da Silva" e estabeleceu que as "florestas consideradas em conjunto" constituíam "bem de interesse comum a todos os habitantes do país".

O Código Florestal de 1934 foi um grande passo para a proteção das florestas e do meio ambiente de maneira geral, porém teve sérias dificuldades de implementação. Essa lei surgiu como uma reação ao desmatamento quando a mata atlântica estava sendo substituída rapidamente por plantios de café.

Em 1964, foi sancionado o chamado Novo Código Florestal Brasileiro. Essa nova lei considerava a floresta e demais formas de vegetação (natural) "bens de interesse comum a todos os habitantes do País". Passa assim a ser de interesse comum da população pelo seu valor

\footnotetext{
${ }^{2}$ Retirado de $O$ "novo" Código Florestal Brasileiro: conceitos jurídicos fundamentais, de Sérgio Ahrens, 2003. Disponível em: $<$ http://www.egov.ufsc.br/portal sites/default/files/anexos/26462-26464-1-PB.pdf>.
} 
QUADRO 1 - EVOLUÇÃO DA LEGISLAÇÃO AMBIENTAL (PRINCIPAIS INSTRUMENTOS DE CRIAÇÃO DAS ÁREAS PROTEGIDAS NO BRASIL).

\begin{tabular}{|c|c|c|}
\hline Período & Instrumentos & Tipologias \\
\hline $1963-1964$ & $\begin{array}{l}\text { Código Florestal (Dec. 2.3793/34); Código de Caça e Pesca (Dec. } \\
\text { 2.3793/34) }\end{array}$ & $\begin{array}{l}\text { Floresta Protetora; Floresta Remanescente; } \\
\text { Floresta de Rendimento; Floresta Modelo ; } \\
\text { Parques de Criação e Refúgio de Animais }\end{array}$ \\
\hline
\end{tabular}

FONTE: Sumarizada a partir de Medeiros, 2006.

intrínseco e não apenas pela sua utilidade (valor de uso) (AHRENS, 2003).

Esta lei ainda não vinculava o conceito de reserva da vegetação natural. Assim, não obrigava a manutenção de áreas como campos e cerrados e outras vegetações naturais. $\mathrm{O}$ código não trazia o termo reserva legal - na verdade, apenas fixava algumas restrições à exploração de áreas de florestas, permitindo o desmatamento da propriedade desde que mantido $50 \%$ da vegetação natural na região amazônica e $20 \%$ no resto do Brasil. Também tinha restrições ao uso da floresta em Áreas de Proteção Permanente-APPs (CUNHA; MELLO-THERY, 2010).

Posteriormente, a Lei ${ }^{\circ} 6.938$ (1981) vai instituir a Política Nacional do Meio Ambiente. A partir desta lei, a vegetação nativa passa a ser vista como um bem jurídico e ambiental.

A Política Nacional de Meio Ambiente (Lei ${ }^{\circ}$ 6.938/81) estabeleceu princípios sobre ações governamentais para manutenção do equilíbrio ecológico; racionalização do uso do solo; planejamento e fiscalização dos recursos ambientais; preservação de áreas representativas; controle e zoneamento; incentivo a pesquisas; recuperação de áreas degradadas, entre outros. Isso objetivava a compatibilização do desenvolvimento econômico-social com preservação da qualidade do meio ambiente, definindo áreas prioritárias para a qualidade do equilíbrio ecológico segundo os interesses da União, Estados e municípios. ${ }^{3}$

\footnotetext{
${ }^{3}$ Disponível em: <http://www4.planalto.gov.br/legislacao/legislacao-1/leis-ordinarias/legislacao/legislacao-1/leis-ordinarias/1987-a-1981\#content>. Acesso em: $13 / 06 / 2012$
} 
A partir deste momento, a "flora" passou a ser tratada como bem jurídico ambiental, um bem que diz respeito aos "direitos de terceira geração", aqueles inerentes aos chamados "interesses difusos" e que incorpora noções como o Direito do Consumidor e o Direito das Minorias Étnicas (AHRENS, 2003).

A lei $n^{\circ} 6.938 / 81$, em seu artigo $2^{\circ}$, estabelece como objetivo:

\begin{abstract}
"a preservação, melhoria e recuperação da qualidade ambiental propícia à vida, visando assegurar no País condições ao desenvolvimento socioeconômico, aos interesses da segurança nacional e à proteção da dignidade da vida humana, atendidos os seguintes princípios: equilíbrio ecológico; racionalização do uso do solo, do subsolo, da água e do ar; planejamento e fiscalização do uso dos recursos ambientais; proteção dos ecossistemas; controle e zoneamento das atividades potencial ou efetivamente poluidoras; acompanhamento do estado da qualidade ambiental; recuperação de áreas degradadas; proteção de áreas ameaçadas de degradação; educação ambiental em todos os níveis de ensino" (BRASIL, 1981).
\end{abstract}

Atualmente, as mudanças na legislação florestal no que diz respeito à reserva legal têm deixado ambientalistas preocupados, assim como outros pontos principais de reforma do Código Florestal.

\subsection{As principais mudanças propostas (Projeto de lei $\left.n^{\circ} 1.876 / 99\right)$ para o novo Código Florestal}

Depois de 1981, várias discussões e debates foram feitos sobre mudanças possíveis no Código Florestal. No início de 2012, a proposta de mudança do Código Florestal foi aprovada na Câmara dos Deputados. O texto do novo Código Florestal passou pelas 3 comissões do Senado (Comissão de Constituição, Justiça e Cidadania; Comissão de Ciência e Tecnologia e Comissão de Agricultura) antes de ir a Plenário. Esse texto aprovado pela Câmara dos Deputados seguiu para sanção presidencial, onde a presidenta Dilma Rousseff vetou os artigos $1^{\circ}$,
43, 61, 76 e 77 e realizou vetos parciais em parágrafos e incisos dos artigos $3^{\circ}, 4^{\circ}, 5^{\circ}$ e 26 .

A maior preocupação dos ambientalistas estava em relação às APPs em áreas urbanas que, segundo o texto modificado pelos deputados (relatoria de Paulo Piau-PMDB-MG), visava promover a flexibilização da exigência de recuperação de APPs, dando liberdade para os Estados brasileiros determinarem a recomposição de suas APPs de acordo com seus interesses e necessidades. O texto original aprovado no Senado delimitava a recomposição de áreas de preservação permanente (APPs) a 15 metros em torno de rios com até 10 metros de largura. ${ }^{4}$

A mudança da gestão do manejo por meio da descentralização da gestão ambiental federal para estadual e municipal também traz modificações na implantação de políticas florestais estaduais e o Código Florestal é fundamental para determinar os rumos da gestão florestal municipal e federal. Outros cinco pontos importantes das mudanças na nova proposta do código são: diminuição das Áreas de Preservação Permanente (APPs), anistia aos crimes ambientais, isenção de reserva legal para imóveis com até 4 módulos fiscais em todo o país, redução da reserva legal na Amazônia em áreas com vegetação, e compensação de áreas desmatadas em um Estado por áreas de floresta em outros Estados ou bacias hidrográficas (SOS FLORESTAS, 2011).

O projeto de lei ( $\left.\mathrm{PL} \mathrm{n}^{\circ} 1.876 / 99\right)$, de relatoria do deputado Aldo Rebelo, iniciou as discussões sobre a reforma do Código Florestal a partir de um texto que trazia proposta de várias alterações.

A proposta de anistia falava sobre o fim da obrigação de recuperar as áreas que foram desmatadas antes de 22 de julho de 2008; topos de morros, margens de rios, restingas, manguezais, nascentes, montanhas e terrenos íngremes estavam entre as mudanças desta proposta no texto do PL 1.876/99 (MIRANDA et al., 2008). A proposta criava a figura da área rural consolidada - aquela ocupação existente até a data definida, com edificações, benfeitorias e atividades agrossilvopastoris em quaisquer espaços, inclusive áreas protegidas (SOS FLORESTAS, 2011).

A maior parte das APPs em topos de morros encontra-se nas regiões Sul e Sudeste, que por natureza possuem

\footnotetext{
${ }^{4}$ Ver Kátia Abreu. "Reforma do Código Florestal”. Disponível em: <http://www12.senado.gov.br/codigoFlorestal>.
} 
relevo mais alto. Na Amazônia, onde o relevo é baixo, de muitas planícies, as APPs têm bastante ocorrência em rios, igarapés e córregos. Sendo assim, as mudanças no Código Florestal no que diz respeito à anistia iriam incidir mais nas regiões Sul e Sudeste. Porém, na região Amazônica, o fim da obrigação de recuperar possíveis áreas já degradadas e a diminuição das matas ciliares em torno dos rios também sofreria impacto das mudanças no Código Florestal.

Segundo o art. $24^{\circ}$ do novo texto do Código Florestal, quando o Programa de Regularização Ambiental - PRA - for implantado e respeitados os termos de compromisso ou de ajustamento de conduta eventualmente assinados, fica assegurada a manutenção das atividades agropecuárias e florestais em áreas rurais consolidadas, localizadas em Áreas de Preservação Permanente e de Reserva Legal, e nas áreas de uso restrito a que se referem os arts. 10, 11 e 12, vedada a expansão da área ocupada, e desde que i) a supressão da vegetação nativa tenha ocorrido antes de 22 de julho de 2008; ii) assegure-se a adoção de práticas que garantam a conservação do solo e dos recursos hídricos; e iii) o proprietário ou possuidor de imóvel rural faça seu cadastro ambiental no órgão estadual do Sisnama. ${ }^{5}$

Em relação às APPs, as mudanças que versavam no novo texto previam a redução da extensão mínima dessas áreas dos atuais 30 metros para 15 metros de faixa marginal e demarcam as matas ciliares protegidas a partir do leito menor do rio e não do nível maior do curso d'água (TRINDADE, 2010). O texto atual do Código Florestal considera área de preservação permanente, as florestas e demais formas de vegetação natural situadas ao longo dos rios ou de qualquer curso d'água "desde o seu nível mais alto". O texto também delimita APP em zonas rurais ou urbanas, a partir da borda do leito menor com largura mínima de 15 metros, para os cursos d'água de menos de 5 metros de largura.

Outro ponto importante discutido foi a isenção de reserva legal (RL) para imóveis com até quatro módulos fiscais em todo o país. Essa mudança iria eliminar a necessidade de recuperação das reservas legais de acordo com o estipulado anteriormente. Enquanto a RL é obrigatória para todos os imóveis rurais nos termos do Código Florestal, o substitutivo do projeto de lei $\mathrm{n}^{\mathrm{o}} 1.876 / 99$ tornou obrigatória a manutenção da RL somente para aqueles com mais de quatro módulos fiscais. A mudança visava proteger o agricultor familiar e os pequenos produtores (TRINDADE, 2010).

Em relação à redução da reserva legal na Amazônia em áreas com vegetação, o projeto anteriormente discutido pretendia diminuir de $80 \%$ para $50 \%$ as áreas de Reserva Legal e as de cerrado de $35 \%$ para $20 \%$ na Amazônia Legal. Tal medida ganhou força, pois, na opinião de algumas camadas do meio rural, tal situação impedia o desenvolvimento da Amazônia, haja vista que existe uma necessidade de expansão da fronteira agrícola (SOS FLORESTAS, 2011).

Outra questão crítica envolvia a compensação de áreas desmatadas em um Estado por áreas de floresta em outros Estados ou bacias hidrográficas. Na regulamentação atual, a compensação tem que ocorrer dentro do mesmo Estado da Federação, o que impossibilita a solução dos passivos nas regiões Sul e Sudeste pela ausência de remanescentes florestais. Segundo o novo Código Florestal, será permitido que isto seja feito em outros Estados da Federação. A proposta aprovada na época permitia o uso de exóticas em até $50 \%$ das áreas - sem distinção de tamanho da propriedade -, aumentando os retornos econômicos possíveis de serem obtidos com a RL. A Servidão Ambiental ou Reserva equivalente também é permitida, conforme o Inciso II, pois possibilita o arrendamento de área de importância ecológica e extensão no mesmo bioma conforme critérios estabelecidos em regulamento. ${ }^{6}$ Sendo assim, se pode dizer que essas alterações no código causarão impactos principalmente nas comunidades locais.

\subsection{Código Florestal e a política florestal no Estado do Pará}

O Código Florestal tem sido essencial para proteger a cobertura florística brasileira. A proposta colocada em

\footnotetext{
${ }^{5}$ Comparativo entre o Código Florestal (Lei n ${ }^{4771 / 65)}$ e o Substitutivo de autoria do deputado Aldo Rebelo ao PL 1876/99; digitalizado em: oglobo.globo.com/.../ comparativo-codigo-florestal-x-proposta-aldor..

${ }^{6}$ Segundo o autor do texto entre o Código Florestal (Lei n ${ }^{\circ 4771 / 65) ~ e ~ o ~ S u b s t i t u t i v o ~ d e ~ a u t o r i a ~ d o ~ d e p u t a d o ~ A l d o ~ R e b e l o ~ a o ~ P L ~ 1876 / 99 ; ~ d i g i t a l i z a d o ~ e m ~ o g l o b o . ~}$ globo.com/.../comparativo-codigo-florestal-x-proposta-aldor...
} 
pauta em 2012 deveria obrigatoriamente incorporar a dimensão da sustentabilidade ambiental do desenvolvimento socioeconômico. Nesse sentido, políticas públicas para proteção das florestas se tornaram fundamentais, principalmente na Amazônia, onde existe uma vasta região de áreas de florestas e diversos recursos naturais (AHRENS, 2003).

A política florestal vem trazendo grandes avanços e importantes alterações na legislação florestal ocorreram nos últimos anos. A publicação da Lei 11.284/2006, de gestão de florestas públicas, é um grande exemplo de mudança na legislação florestal que inovou por meio do processo de descentralização da gestão ambiental da União para os Estados e Municípios; com isto, aceleraram o processamento de normatização das atividades florestais (MARTINS, 2010).

A partir desta lei, pela primeira vez no Brasil abriu-se a possibilidade de empresas e cooperativas explorarem os recursos madeireiros das Florestas Nacionais (FLONAS) por meio de um plano de manejo. Segundo Bernardo (2006), a lei tem o objetivo de ordenar o acesso aos recursos florestais existentes em terras públicas, através da concessão de áreas à iniciativa privada, por tempo determinado, com apresentação de um plano de manejo e de sustentabilidade. Das políticas formuladas para a indústria madeireira, a mais expressiva é a Política Nacional de Florestas do Ministério do Meio Ambiente. Esta política se baseia no fato de o setor madeireiro ser uma fonte importante e significativa de empregos e geração de renda para a sociedade amazônica, que se encontra limitada pela ausência de florestas disponíveis para exploração. Tal política teria como alvo a criação, até o ano de 2010, de 50 milhões de hectares de florestas nacionais em áreas de baixa densidade populacional (VERÍSSIMO, 2002).

Houve diversos avanços na política florestal nos Estados brasileiros. No Estado do Pará, segundo Martins (2010), o Plano Safra Florestal Madeireira do Estado do Pará do IDEFLOR conseguiu implementar várias ações direcionadas à política florestal. ${ }^{7}$ Entre essas ações estão: lançamento do Plano Anual de Outorga Florestal (PAOF) Estadual, apresentando como áreas passíveis para concessão florestal mais de 8 milhões de hectares de florestas públicas; criação do IDEFLOR (Lei nº 6.963/2007); publicação de alguns decretos (celebração de contratos de transição para exploração florestal em áreas públicas estaduais, assim como a criação da Comissão de Gestão de Florestas Públicas - COMEF); aprovação do macro Zoneamento Ecológico Econômico (ZEE) na região Oeste do Pará (Lei n $\left.{ }^{\circ} 7.423 / 2009\right)$; lançamento do programa 1 bilhão de árvores; instituição do complexo geoeconômico e social no Distrito Florestal; Sustentável DFS e Br 163; mapeamento de florestas públicas, entre outros.

Em meio a estas ações no Estado do Pará, as competências sobre a gestão ambiental do Estado têm ficado sob a responsabilidade da Secretaria de Estado de Meio Ambiente (SEMA) e do Instituto de Desenvolvimento Florestal do Estado do Pará (IDEFLOR).

A SEMA tem atuado em conjunto com o IDEFLOR de diversas formas e em questões muito próximas. Os temas relacionados a Monitoramento e Licenciamento Ambiental por meio do sistema de concessões de áreas florestais para uso privado têm ficado a cargo da SEMA e o monitoramento, gestão e concessão das áreas de florestas públicas têm ficado a cargo do IDEFLOR. A implantação e administração efetiva das concessões propostas na Política Nacional de Florestas são centrais para uso sustentável da floresta e também ajudam no combate a potenciais infrações (uso ilegal da terra e desmatamento) das florestas primárias Amazônicas existentes. ${ }^{8}$

A decisão para adotar concessões está baseada na premissa de que aumentará a rentabilidade da exploração madeireira e que o governo poderá melhor monitorar e controlar as atividades das indústrias madeireiras se a exploração for realizada em florestas públicas, reduzindo a exploração ilegal e, assim, aumentando a adoção de práticas de manejo florestal.

Algumas das políticas que a SEMA tem implantado no Estado estão ligadas à preservação de unidades de conservação, educação ambiental e projetos de gestão

\footnotetext{
7 Retirado do texto de Martins, 2011. IDEFLOR-Plano Safra Florestal Madeireira do Pará, p. 45-46. Além destes pontos em destaque, encontram-se outros referentes à política florestal do Pará no documento de origem.

${ }^{8}$ Presente no quadro 2, p. 61, no artigo de Lima et al. 2003 - "Florestas familiares: um pacto socioambiental entre a indústria madeireira e a população rural carente da Amazônia".
} 
ambiental. O Sistema Integrado de Monitoramento e Licenciamento Ambiental - SIMIAM - e o Sistema de Comercialização e Transporte de Produtos Florestais - SISFLORA - trouxeram, respectivamente, maior transparência quanto às ações desempenhadas pelo órgão e maior controle do comércio de produtos florestais. ${ }^{9}$

Um dos projetos da SEMA é o Projeto de Gestão Ambiental Integrada do Estado do Pará (PGAI/PA) que tem como objetivo implementar um modelo de gestão ambiental integrada em duas regiões do Estado, contemplando 31 municípios nas áreas do Moju-Capim e Tapajós. O PGAI/PA é coordenado pela SEMA e tem cooperação de várias instituições ligadas ao meio ambiente, como: Ministério Público Estadual, as Secretarias de Meio Ambiente das Prefeituras das áreas prioritárias, Polícia Militar, Polícia Civil, Instituto Brasileiro do Meio Ambiente e dos Recursos Naturais Renováveis (IBAMA), Secretaria de Estado e Agricultura (SAGRI), Serviços, Engenharia e Instalação de Comunicações Ltda. (SEICOM), Secretaria de Estado e Saúde Pública (SESPA) e as entidades não governamentais Grupos de Trabalho Amazônico (GTA) e o Fórum da Amazônia Oriental (FAOR). ${ }^{10}$

O IDEFLOR atualmente está em um processo de concessão na Flota Paru no Estado do Pará. Flotas são Florestas Estaduais, considerada Unidades de Conservação de Uso Sustentável. Tais unidades, criadas pelo governo, têm como objetivo (VEDOVETO, 2011) "proteger a natureza, promover o desenvolvimento sustentável e defender os direitos das populações locais". Esta Flota localiza-se no Estado do Pará, na Calha Norte do rio Amazonas. De acordo com a autora, as atividades planejadas na Flota estão previstas para os anos de 2011 a 2015 e estão descritas em sete programas, que são: a) gestão da unidade; b) geração de conhecimento; c) proteção dos recursos naturais; d) manejo dos recursos naturais; e) uso público; f) valorização das comunidades; g) efetividade de gestão (VEDOVETO, 2011).

\subsubsection{A reforma do Código Florestal para o Estado do Pará e os impactos sobre o desmatamento}

No Pará, a compensação de áreas desmatadas em um estado por áreas de floresta em outros estados e a redução da reserva legal na Amazônia de 80 para 50\% vão permitir o avanço do desmatamento e ocupação sobre uma área maior de floresta, além de criar um mecanismo de isenção para o madeireiro que desmatou uma área de floresta local, pois, com a compensação, o proprietário poderá compensar o dano ambiental em outros Estados ou em dinheiro.

O PIB e a exportação de madeira mostram que o setor madeireiro tem grande importância para o Estado, gerando altos lucros para os empresários do setor e com relevante geração de emprego para a população, com destaque para o Leste do Pará (Tabela 1) (VERÍSSIMO et al., 1992; VERÍSSIMO et al., 1995).

TABELA 1 - RENDA, EMPREGO, EXTRAÇÃO ANUAL E NÚMERO DE INDÚSTRIAS POR POLOS MADEIREIROS, 2010

\begin{tabular}{|c|c|c|c|c|}
\hline $\begin{array}{c}\text { Polo } \\
\text { madei- } \\
\text { reiro }\end{array}$ & $\begin{array}{c}\text { Número } \\
\text { de } \\
\text { indústrias }\end{array}$ & $\begin{array}{c}\text { Extração } \\
\text { anual de toras } \\
\text { (milhares de } \\
\mathbf{m}^{3} \text { ) }\end{array}$ & $\begin{array}{c}\text { Empregos } \\
\text { Gerados }\end{array}$ & $\begin{array}{c}\text { Receita } \\
\text { bruta } \\
\text { (US\$ } \\
\text { milhões) }\end{array}$ \\
\hline $\begin{array}{c}\text { Centro do } \\
\text { Pará }\end{array}$ & 132 & 895 & 16.078 & 161,8 \\
\hline $\begin{array}{c}\text { Estuário } \\
\text { Paraense }\end{array}$ & 491 & 1.870 & 24.269 & 282,1 \\
\hline $\begin{array}{c}\text { Leste do } \\
\text { Pará }\end{array}$ & 266 & 2.983 & 38.558 & 490,7 \\
\hline $\begin{array}{c}\text { Oeste do } \\
\text { Pará }\end{array}$ & 139 & 724 & 10.952 & 137,5 \\
\hline Sul do Pará & 39 & 127 & 2.567 & 22,1 \\
\hline Pará & 1.067 & 6.599 & 92.423 & $1.094,2$ \\
\hline
\end{tabular}

FONTE: Adaptado de IMAZON, 2010.

Por outro lado, as regiões Sul e Sudeste do Brasil são os maiores consumidores da madeira amazônica com $80 \%$ vindo da produção amazônica (VERÍSSIMO;

\footnotetext{
${ }^{9}$ Informações contidas na página oficial da SEMA-PA, em <http://www.sema.pa.gov.br>. Acesso em: 13/10/2011. Coordenador Técnico do Projeto GAI/Pa: Antônio Augusto Ferreira Filho.

${ }^{10}$ Idem.
} 
LIMA; LENTINI, 2002), sendo que os grandes centros de exploração madeireira da Amazônia Oriental (ao longo da Rodovia Belém-Brasília) e dos Estados de Mato Grosso e Rondônia, por exemplo, surgiram, primeiramente, em função da proximidade dos principais mercados domésticos do Centro-Sul.

O setor produtivo de madeira e derivados no Pará vem enfrentando dificuldades nas últimas décadas apesar do seu enorme potencial produtivo. As dificuldades estão em tornar seus produtos competitivos nos mercados local, nacional e mundial, bastante globalizados. Esses desafios requerem políticas vinculadas à política florestal que auxiliem nos ganhos de competitividade e permitam que a atividade florestal madeireira se estabeleça com bases fortes que permitam vencer os desafios impostos à atividade (MARTINS, 2011). Logo, as mudanças no Código Florestal podem permitir mudanças na condução do setor florestal, abrindo portas para o crescimento da atividade madeireira, juntamente com a exploração ilegal da madeira, isso em virtude da alta demanda deste produto florestal.

\subsection{A discussão do Código Florestal após aprovação final}

Depois de diversos debates políticos em torno da aprovação do Código Florestal, sua proposta de reforma (PL 1.876/99) e seus possíveis impactos para o meio ambiente (Amazônia principalmente), no dia 25 de maio de 2012 o novo Código Florestal brasileiro foi aprovado (Lei Federal $n^{\circ}$ 12.651/12). O texto final foi aprovado na Câmara dos Deputados e posteriormente foi levado à sanção presidencial. O texto trouxe algumas mudanças importantes para o cenário agroambiental do Brasil. De acordo com ambientalistas e defensores dos recursos naturais, o texto final aprovado representa retrocessos nas políticas ambientais brasileiras.

Um dos grandes retrocessos argumentados pela camada ambientalista diz respeito às APPs, onde houve redução das faixas de APP ao longo de cursos d'água, uma vez que foi adotado o critério de mensuração a partir da borda da calha do leito regular, ao invés do nível mais alto, que constava na Lei no 4.771/1965 (Código Florestal anterior). Pelo projeto original do novo Código Florestal (PL 1.876/99), já era prevista a redução da extensão mínima dos atuais 30 metros para 15 metros de faixa marginal e se demarcava as matas ciliares protegidas a partir do leito menor do rio. Essa redução permaneceu no novo texto, porém a mudança com relação ao critério do leito menor tem sido a maior crítica no que se refere à APP no novo Código Florestal. Além disso, o atual texto autorizou a continuidade das atividades agrossilvopastoris, de ecoturismo e de turismo rural em APP nas áreas rurais consolidadas até 22 de julho de 2008, o que se configurou em anistia aos desmatadores das áreas de APPs até aquela data. O projeto original já introduzia essa possibilidade do fim da obrigação de recuperar as áreas que foram desmatadas antes de 22 de julho de 2008 incluindo topos de morros, margens de rios, restingas, manguezais e nascentes. ${ }^{11}$

Outras mudanças que flexibilizaram o Código Florestal referem-se à admissão de aquicultura em APP, em imóveis de até 15 hectares, avaliação de casos em que poderá haver redução da reserva legal de $80 \%$ para $50 \%$ (quando o Município tiver mais de 50\% da área ocupada por unidades de conservação ou quando o Estado tiver ZZE aprovado e mais de $65 \%$ do seu território ocupado por unidades de conservação) e à abertura para a compensação de áreas desmatadas em um Estado por áreas de floresta em outros Estados, sem observar as bacias hidrográficas e características individuais de cada bioma. ${ }^{12}$

Em 2013, o Código Florestal completou um ano em vigor e novas discussões acerca de sua aplicação efetiva para os Estados brasileiros vêm tangendo os debates sobre o uso do solo brasileiro entre ambientalistas e governistas. A implantação das ferramentas que vão determinar as áreas de preservação permanente ainda está sendo avaliada.

Representantes de ONGs e diversos institutos ambientais do Brasil - Instituto de Pesquisas Ambientais da Amazônia (IPAM), SOS Mata Atlântica, Instituto Centro

\footnotetext{
${ }^{11}$ Ver em JURAS, I. A. G. M.; GANEN, R. S. Código Florestal: tabela comparativa dos textos da Câmara, do Senado e redação final. Disponível na Biblioteca Digital da Câmara dos deputados: <http://bd.camara.gov.br>.

${ }^{12}$ Idem.
} 
de Vida (ICV) e Instituto Socioambiental (ISA), entre outros - estão acompanhando o desenrolar das discussões sobre a aplicabilidade do novo Código Florestal. A regulamentação do código depende da superação de alguns entraves que dificultam tornar a lei prática e eficaz nas áreas protegidas, como a falta de recursos humanos capacitados para atuar nas comunidades rurais e gestão nos órgãos ambientais, cadastro e monitoramento de todas as propriedades rurais existentes nos Estados e municípios por meio do CAR - Cadastro Ambiental Rural e descentralização das atividades florestais antes nas mãos somente do IBAMA. ${ }^{13}$

De acordo com a mídia, algumas ONGs encaminharam uma carta para a Ministra do Meio Ambiente, Izabella Teixeira, ressaltando o interesse em participar ativamente do processo de acompanhamento e monitoramento do Código Florestal através da coleta e análise de informações que apontem indicadores sobre como está a implementação do CAR e dos Planos de Regularização Ambiental em todas as regiões do país. Esse grupo que realizará a coleta e análise de dados foi chamado de Grupo de Acompanhamento da Implantação do Código Florestal e também fará sugestões e propostas de regulamentação da legislação. Além disso, números anteriores divulgados pelas organizações mostram que, desde a aprovação do código, nenhum Estado brasileiro havia aprovado o Programa de Regularização Ambiental - 4,5 milhões de propriedades rurais, aproximadamente, que ainda precisavam ser registradas no Cadastro Ambiental Rural. ${ }^{14}$

\section{Resultados - avaliação dos stakeholders}

Apesar de a mídia ter apresentado um enorme debate sobre a proposta de mudança no Código Florestal nos últimos anos (2011 e 2012), um estudo mais sistemático com os stakeholders sobre avaliação do código e suas mudanças é importante para identificar a percepção desse grupo sobre as mudanças e os impactos do novo Código
Florestal, bem como aprofundar o entendimento das mudanças na legislação. Esses grupos de interesse avaliaram o processo de transição do Código Florestal; o impacto das mudanças na lei sobre pesquisas e setores de trabalho; as mudanças na gestão de manejo (descentralização da gestão ambiental da União para Estados e municípios); a estrutura e adequação dos órgãos ambientais estaduais (Estado do Pará) - IBAMA, SEMA e IDEFLOR e as deficiências da legislação ambiental brasileira.

\subsection{Mudanças na legislação florestal}

Com relação às mudanças na legislação florestal, as entrevistas apontaram que $47,05 \%$ acham que as mudanças propostas foram positivas, $47,05 \%$ negativas e 5,90\% acham que foram em parte positivas e em parte negativas, sendo que a maioria dos entrevistados que responderam positivo são de origem dos órgãos ambientais.

Eles acreditam que as mudanças da legislação apontam um futuro mais favorável a determinados segmentos do setor privado. Porém, eles também acham que as mudanças propostas no novo Código Florestal não apresentam sinais de desburocratização ou de aplicabilidade com maior eficiência.

Os entrevistados em geral acham que o código tem ficado bem mais restritivo a partir de 1981, quando foi sancionada a Lei $\mathrm{n}^{\mathrm{o}}$ 6.938, que estabeleceu a Política Nacional do Meio Ambiente. Para eles, do ponto de vista técnico a legislação tem evoluído. Nesse sentido, há uma atuação mais restritiva ao setor madeireiro. O setor, por sua vez, vem se enquadrando às normas exigidas pelos órgãos de gestão ambiental. Uma recente modificação considerada importante foi a definição de áreas de concessão. Segundo os entrevistados, o grande entrave para os empresários é a pouca oferta de áreas legais para exploração e de matéria-prima para exploração. A nova lei de concessão florestal contribui para que novas áreas sejam legalizadas, permitindo uma fonte de suprimento de madeira legal.

\footnotetext{
${ }^{13}$ Ver em Portal Agência Brasil - Empresa Brasil de Comunicação. Disponível em: <http://agenciabrasil.ebc.com.br/noticia/2013-05-21/ongs-vao-monitorar-regulamentacao-e-implementacao-do-codigo-florestal $>$. Acesso em: 27/05/2013.

${ }^{14}$ Idem .
} 
Para os técnicos, nos últimos anos a legislação florestal trouxe normatização das áreas públicas federais e estaduais e vários Estados vêm desenvolvendo suas leis estaduais. Um entrevistado do órgão ambiental ressalta que a criação do IDEFLOR (Lei 6.963) ${ }^{15}$ foi fundamental para a gestão das florestas públicas que podem ser exploradas a partir da concessão florestal.

\subsection{Reforma do Código Florestal}

Atualmente, o processo de reforma do Código Florestal tem ganhado muito destaque e para isso foi feito um levantamento junto aos entrevistados sobre as principais mudanças que o projeto de lei PL 1.876/99 propunha para o Código Florestal. Perguntados sobre a diminuição das Áreas de Proteção Permanente (APPs), $5,88 \%$ responderam que a mudança é positiva, $(52,94 \%)$ responderam ser negativa e outros $41,18 \%$ não se manifestaram sobre o assunto. $\mathrm{O}$ mesmo resultado foi obtido para anistia aos crimes ambientais e isenção de reserva legal para imóveis com até quatro módulos fiscais.

A maioria que avaliou como negativa a redução das APPs explica que elas são essenciais para a proteção dos cursos d'água e que os casos passíveis de exceção já foram identificados pela academia. Os entrevistados que consideram a redução positiva disseram que o importante é que realmente sejam pagos os danos com serviços ambientais porque os autuados recorrem da multa e a demora em ter uma sentença final é grande.

Sobre isenção de reserva legal para imóveis com até quatro módulos fiscais, os que consideraram essa mudança negativa disseram que a diferenciação não deve ser feita pelo tamanho do imóvel, mas por sua função socioambiental, ou seja, pelas características do ecossistema do local do imóvel e do tipo de uso realizado pelo detentor do imóvel. Vários afirmam que a propriedade rural tem que ter múltiplas atividades para aumentar a renda e que o proprietário deve pensar em alguma forma de ter essa reserva legal até em forma de condomínio. Outros afirmam que há o risco de esse proprietário rural adquirir grandes áreas por meio da compra de várias áreas pequenas para fugir à obrigação de manter a RL.

Para a redução da reserva legal na Amazônia em áreas com vegetação de $80 \%$ para $50 \%$ e compensação de áreas desmatadas de passivos florestais, $17,65 \%$ responderam que as mudanças são positivas, $41,18 \%$ acham negativas e $47,05 \%$ não responderam. Os que apontaram como negativa argumentaram que o bioma em questão é frágil e há possibilidades de uso sustentável nos $20 \%$ de área em que são permitidos desmatar nas áreas de florestas nas propriedades. Os que responderam como positiva ressaltaram que apenas se deve dar a diminuição da reserva legal para exploração florestal se for a favor de pequenos produtores.

Um grupo entende que compensação de áreas desmatadas de passivos florestais é negativa e que não deveria existir essa proposta de mudança, porque dessa forma a compensação pode ocorrer em áreas de qualidade e importância ecológica diferente.

\subsection{Adequação dos órgãos ambientais às novas leis ambientais}

Os Estados brasileiros vêm ganhando mais autonomia sobre as questões ambientais, muito em função da Lei $n^{\circ} 11.284 / 2006$ de gestão de florestas públicas, que inovou por meio do processo de descentralização da gestão florestal da União para os Estados e Municípios e, com isto, acelerou a normatização das atividades florestais (MARTINS, 2010). Para a descentralização da gestão ambiental para os Estados brasileiros no geral, $41,18 \%$ acharam positiva, $35,29 \%$ acharam negativa, $5,88 \%$ não se manifestaram sobre o assunto e $17,65 \%$ acreditam que a lei não faz diferença sobre a gestão ambiental. Analisando apenas as instituições de ensino e pesquisa, $71,42 \%$ acham positiva, sendo que o restante $28,58 \%$ acreditam não fazer diferença a mudança da gestão ambiental, considerando ser um processo natural. Somente para os órgãos de gestão ambiental, $33,33 \%$ acham positiva, sendo o restante negativa ou não souberam responder.

\footnotetext{
${ }^{15}$ O Instituto de Desenvolvimento Florestal do Estado do Pará - IDEFLOR - foi criado por meio da Lei Estadual no 6.963 , de 16 de abril de 2007 , atendendo exigência da Lei Federal n ${ }^{\circ} 11.284$, de 02 de março de 2006, que versa sobre a Gestão de Florestas Públicas.
} 
Sobre a mudança de IBAMA para SEMA e IDEFLOR para implantação da legislação de manejo no Estado do Pará, os pesquisadores disseram que a descentralização da gestão ambiental é positiva, exatamente em função das políticas micromunicipais que se interagem, tendo poder de polícia para fiscalizar ou expedir algum ato contra os agentes criminosos. Nesse contexto, as Organizações Estaduais do Meio Ambiente - OEMAs adquirem maior importância, pois elas conhecem as necessidades locais. Porém houve aqueles que acharam que a gerência deve ser integrada, a exemplo de IBAMA-ICMBIO-SEMA. Para alguns pesquisadores entrevistados, o Estado não pode legislar sem integração, sendo que cada órgão deve atuar dentro de sua competência, mas deve se integrar para evitar a desintegração entre as tarefas desempenhadas. Eles acreditam que esse processo de mudanças ainda não foi capaz de criar uma estrutura estadual eficaz. Nesse sentido o licenciamento ambiental enfrenta problemas e a transição da gestão do nível federal para a esfera estadual foi feita sem a necessária reestruturação e alocação de recursos humanos e financeiros.

Os técnicos de maneira geral consideraram que a descentralização foi positiva porque o IBAMA, como órgão federal, deve fiscalizar e monitorar o território nacional, que possui uma diversidade grande entre as regiões, sendo que o ecossistema amazônico não é tratado de forma adequada. Para eles, o processo de descentralização é natural, contudo, os órgãos de esferas estaduais e municipais ficam sujeitos às pressões políticas, o que impacta negativamente, na maioria das vezes, a tomada de decisões.

\subsection{Descentralização da gestão ambiental: Estado do Pará}

Com base nessas entrevistas detalhadas, os entrevistados foram questionados se o Estado do Pará está preparado para assumir maior responsabilidade sobre a gestão ambiental com o processo de descentralização. Os resultados mostraram que, no geral, $23,53 \%$ acreditam que o Pará está preparado para assumir maior responsabilidade sobre a gestão ambiental em função da descentralização, $17,65 \%$ acham que não, $52,94 \%$ não responderam e 5,88\% disseram que a descentralização é parcialmente positiva. Somente nas instituições de pesquisa, 50\% acham que o Estado não está preparado para a descentralização da gestão ambiental, sendo que não houve opinião favorável sobre o assunto ou não responderam. Nos órgãos de gestão esse número foi menor, onde em torno de um sexto $(16,67 \%)$ acreditam que o Estado do Pará não está preparado, enquanto o mesmo percentual acha que o Estado está preparado, sendo o restante a percentagem de abstenções.

A exploração no Estado do Pará é grande e para isso foi perguntado sobre o sistema de concessão florestal para exploração madeireira. Os que disseram que o sistema de concessão florestal melhorou a gestão do recurso florestal representaram $17,65 \%$, em oposição aos $11,76 \%$ que disseram que o sistema de concessão piorou a gestão do recurso. Outros $11,76 \%$ não fizeram diferenciação, mesmo resultado não têm opinião e $41,17 \%$ não responderam.

\subsection{Estrutura e ambiente de trabalho}

Sobre o aspecto institucional, foi perguntado se os entrevistados estão encontrando dificuldades em seu trabalho e/ou pesquisa devido às mudanças na legislação florestal. Tanto para pesquisadores e técnicos as dificuldades são grandes. Alguns entrevistados falaram que as dificuldades são grandes, pois as empresas estão impedindo o pesquisador de ter acesso aos dados e sítios para a pesquisa. Outros disseram que não há dificuldades, pois não trabalham diretamente com a questão florestal. As principais dificuldades que os técnicos vêm encontrando em seu trabalho em relação à legislação ambiental são com novas instruções normativas e a descentralização da gestão ambiental em relação às atividades administrativas e fiscalizadoras.

Ainda sobre o impacto das mudanças no trabalho, os entrevistados foram questionados como se ajustam quando sai uma nova lei e como ela afeta seu trabalho. De maneira geral $17,65 \%$ disseram que essas mudanças afetam bastante, $29,41 \%$ afirmam que não afetam $11,76 \%$ não sabe e afetam pouco e a grande maioria $(41,17 \%)$ não respondeu. A maioria que afirma que não há grande impacto não trabalha diretamente com as leis florestais e 
os que disseram que afetam bastante são todos de órgãos de gestão ambiental.

\subsection{Deficiências da legislação ambiental brasileira}

Sobre qual seria o maior problema da legislação ambiental, os pesquisadores responderam que há uma desarticulação entre a atividade produtiva e as políticas públicas em termos de investimentos e financiamentos específicos para ela. Também foi dito que falta fiscalização para garantir a implantação da legislação. Foi dito também que deve haver capacitação da sociedade e das populações tradicionais que estão próximas ou no interior de áreas protegidas e que dependem do capital econômico e social das empresas exploradoras de recursos florestais, principalmente da madeira, juntamente com maior esclarecimento à sociedade civil da importância da manutenção da floresta e das tecnologias e conhecimentos que são capazes de promover o manejo adequado.

Os técnicos do governo disseram que para que a legislação ambiental seja efetiva e eficaz é necessário mais monitoramento e educação ambiental. Sugestões de educação ambiental com abordagem interdisciplinar nas escolas foram feitas no intuito de mostrar como o individuo pode afetar o seu futuro sem preservação.

\section{Conclusão}

A pesquisa mostrou que não há consenso sobre as alterações sofridas pela legislação florestal, pois foi obtida a mesma proporção para os que consideram as mudanças positivas e negativas. Isso demonstra, de maneira geral, que a legislação precisa melhorar em diversos aspectos, como desburocratização das atividades administrativas e aplicabilidade das leis, para ser considerada ideal. Os pesquisadores e técnicos discordaram na maioria dos questionamentos. Os pesquisadores se mostraram mais pessimistas em relação à reforma do Código Florestal e à descentralização da gestão florestal para os Estados e municípios. Os técnicos demonstram ser mais favoráveis às mudanças na legislação e no aspecto da descentralização da gestão florestal.
Quando consultados sobre Código Florestal relacionado à regulamentação das faixas de APP, assim como definição da área de reserva legal, a maior parte dos entrevistados acha inadequadas tais reformas. Os entrevistados também acham inadequadas as mudanças no Código Florestal referentes à anistia aos crimes ambientais e compensação de áreas desmatadas de passivos florestais, porém grande parte não quis se manifestar devido ao pouco conhecimento sobre o tema.

Em relação à concessão florestal, parte dos entrevistados achou que essa lei melhorou a gestão do recurso porque permitiu a legalização de parte da madeira que abastece a indústria madeireira. Sobre a descentralização da gestão ambiental no Estado do Pará, no geral foi avaliada a pouca adequação e preparação do órgão ambiental estadual para fazer a gestão ambiental. Ao mesmo tempo, também foi avaliado que a descentralização da gestão ambiental é um processo importante e necessário.

Durante esse processo de apresentação e votação do novo Código Florestal, a mídia mostrou uma grande discórdia entre os agentes sociais, como ambientalistas e produtores. Esse trabalho buscou analisar de que maneira os pesquisadores e gestores se colocam em relação a esse debate. $\mathrm{O}$ resultado mostra que mesmo entre o público que trabalha com a pesquisa ou com a regulamentação da atividade não há também consenso. Em geral, quase metade tem uma posição contra as mudanças no tamanho da reserva legal e das APPs. Entretanto, o clima controverso sobre o assunto pode ser revelado pelo alto número de pessoas que não responderam, optaram por não responder ou não quiseram emitir suas opiniões sobre as questões mais polêmicas.

É preciso agilidade nas negociações entre governo, estados e municípios para regulamentação do novo Código Florestal brasileiro. Se, por um lado, o novo código traz retrocessos na proteção dos recursos naturais, por outro, regulamenta as atividades exploratórias, como a madeireira, em diversas regiões do país, e isso é importante para normatização das atividades florestais no país. A intervenção de grupos ambientalistas nas discussões do novo código é importante para o ajuste das regras ambientais e transparência na tomada de decisões por parte dos órgãos ambientais frente à sociedade civil. 


\section{Referências}

AHRENS, S. O “novo” Código Florestal brasileiro: conceitos jurídicos fundamentais. 2003. Disponível em: <http://www. egov.ufsc.br/portal/sites/default/files/anexos/26462-26464-1PB.pdf>. Acesso em: 10/09/2011.

BERNARDO, C. Comentários à Lei $n^{\circ} 11.284 / 2006$. Publicado em set. 2006. Disponível em: <http://iedhma.org.br/artigos/ art003.htm>. Acesso em 13/10/2011.

BRASIL. Comparativo entre o Código Florestal (Lei 4771/65) e o Substitutivo de autoria do Deputado Aldo Rebelo ao PL 1.876/99. Disponível em: <http://oglobo.globo.com/pais/ arquivos/comparativo-codigo-florestal-x-proposta-aldorebelo. pdf>. Acesso em: 02/09/2011.

. Lei $n$. 6.938, de 31 de agosto de 1981. Dispõe sobre a Política Nacional do Meio Ambiente, seus fins e mecanismos de formulação e aplicação, e dá outras providências. Diário Oficial da União, 02 de set. 1981. Disponível em: <http:// www81.dataprev.gov.br/sislex/paginas/42/1981/6938.htm>. Acesso em: 11/05/2012.

CUNHA, P. R.; MELLO-THERY, N. A. de. A reserva legal no contexto da política nacional de florestas. In: ENCONTRO NACIONAL DA ANPPAS, 5., Florianópolis, Santa Catarina, 2010. [Trabalho publicado em out. 2010]. Disponível em $<$ http://www.anppas.org.br/encontro5/cd/artigos/GT3-288210-20100904192616.pdf>. Acesso em: 18/10/2011.

LIMA, E.; LEITE, A.; NEPSTAD, D.; KALIF, K.; AZEVEDO-RAMOS, C.; PEREIRA, C.; ALENCAR, A; LOPES, U; MERRY, F. Florestas familiares: um pacto socioambiental entre a indústria madeireira e a população rural carente da Amazônia. Instituto de Pesquisa Ambiental da Amazônia (IPAM). Belém, Brasil, 2003. 70 p.

MARTINS, D. (Coord.). Plano safra florestal madeireira do Estado do Pará. Instituto de Desenvolvimento Florestal do Pará. IDEFLOR, Belém, 2010. Disponível em: < http://www. ideflor.pa.gov.br/files/Minuta_Plano_safra.pdf $>$. Acesso em: 20/10/2011.

MEDEIROS, R. Evolução das tipologias e categorias de áreas protegidas no Brasil. Ambiente \& Sociedade, v. IX, n. 1, jan./ jun. 2006. Disponível em: <http://www.scielo.br/pdf/asoc/ v9n1/a03v9n1.pdf $>$. Acesso em: 24/08/2011.

MIRANDA, E. E.; CARVALHO, C. A.; SPADOTTO, C. A.; HOTT, M. C.; OSHIRO, O. T.; HOLLER, W. A. Alcance territorial da legislação ambiental e indigenista. Campinas: Embra- pa Monitoramento por Satélite, 2008. Disponível em: <http:// www.alcance.cnpm.embrapa.br/>. Acesso em: 09/10/2011.

MONTEIRO, J. L. C. Legislação Ambiental. In: PINHEIRO NETO ADVOGADOS. São Paulo. Publicado em Jan. 2007. Disponível em <http://www.pinheironeto.com.br/upload/ tb pinheironeto_livreto/pdf/070507111358ambiental 2007. pdf>. Acesso em: 02/10/2011.

SOBRAL, L.; VERÍSSIMO, A.; LIMA, E.; AZEVEDO, T.; SMERALDI, R. Acertando o alvo 2: consumo de madeira amazônica e certificação florestal no Estado de São Paulo. Belém: IMAZON, IMAFLORA, Amigos da Terra, 2002.

SOS FLORESTAS. Código florestal: entenda o que está em jogo com a reforma da nossa legislação ambiental. Disponível em: <www.ipam.org.br>. Acesso em: 18/09/2011.

TRINDADE, G. Áreas de preservação permanente e reserva legal: análise comparativa entre o atual Código Florestal Federal (Lei $\left.n^{\circ} 4.771 / 65\right)$ e o Substitutivo do PL n $1.876 / 1999$ (novo Código Florestal). In: LAVRATI, P. (Org.); PRESTES, V. Direito e mudanças climáticas: reforma do Código Florestal, limites jurídicos. São Paulo, 2010, 189 p. Disponível em: $<$ http://www.observatorioeco.com.br/wp-content/uploads/ up/2010/12/cadigo-florestal.pdf>. Acesso: 04/06/2012.

VEDOVETO, M. et al. Cartilha do plano de manejo da floresta estadual do Paru. Belém: SEMA; IMAZON, 2011. p. 34.

VERÍSSIMO, A.; BARRETO, P.; MATTOS, M.; TARIFA, R.; UHL, C. Logging impacts and prospects for sustainable forest management in an old Amazonian frontier: the case of Paragominas. Forest Ecology and Management, v. 55, p. 169-199, 1992.

; __ _ _ TARIFA, R.; UHL, C. Extraction of a highvalue natural resource from Amazon: the case of mahogany. Forest Ecology and Management, v. 72, p. 39-60, 1995.

; LIMA, E.; LENTINI, M. Polos madeireiros do Estado do Pará. Belém; IMAZON, 2002. Disponível em: <http://www. amazonia.org.br/arquivos/34293.pdf> . Acesso em: 24/10/2011.

Recebido em 21 de outubro de 2012. Aceito em 21 de junho de 2013. Publicado em junho de 2013. 